\title{
Complex-Conjugate Control of A Linear Magnetic- Geared Permanent-Magnet Machine for Archimedes Wave Swing Based Power Generation
}

\author{
Wenlong Li and K.T. Chau \\ Dept. of Electrical and Electronic Engineering \\ The University of Hong Kong \\ Hong Kong, China \\ wlli@eee.hku.hk
}

\begin{abstract}
This paper deals with control of a linear magneticgeared permanent-magnet machine for Archimedes wave swing based wave power generation using maximum power point tracking (MPPT). Firstly, the linear magnetic-geared permanentmagnet generator structure is presented. The machine modeling is established based on finite element analysis (FEA). Secondly, by analyzing the dynamic model of wave power, the MPPT algorithm for direct-drive wave power generation is developed. Then, the performance for maximizing wave power absorption is verified and evaluated by the circuit simulator. The results verify that the MPPT algorithm is valid for the direct-drive wave power generation.
\end{abstract}

Keywords-Linear generator; magnetic gear; maximum power point tracking; complex-conjugate control; wave power generation

\section{INTRODUCTION}

As a clean and sustainable resource, wave energy attracts more and more attention due to fossil energy crisis and the negative side effects of the traditional resources. Consequently, the development of wave power generation becomes a hot issue. Since direct-drive wave power generation technique eliminates mechanical gearboxes and the corresponding mechanical devices for speed, force and motion conversion, it has been widely accepted in recent years. Due to the lowfrequency and huge-force characteristics of the wave power, selection of a suitable electrical generator is vital for this application [1]-[4]. Due to the high-force/torque density and high efficiency, permanent-magnet (PM) machines are the best candidates for this application [5]-[10]. However, for ultra-lowspeed machine design, PM machines have some limitations in manufacture. In recent years, magnetic gears have been proposed and developed which can transmit the torque and speed without physical contact [11]-[18]. With the magnetic gears, the low-speed PM machines design can be converted into a high-speed machine design issue [19]-[22]. Recently, a linear magnetic-geared permanent magnet machine was proposed and evaluated which shows its effectiveness for direct-drive wave power generation [23].

The purpose of this paper is to implement a linear magnetic-geared permanent-magnet generator for direct-drive

This work was supported by a grant (Project No. HKU710711E) from the Hong Kong Research Grants Council, Hong Kong Special Administrative Region, China. wave power generation. By using maximum power point tracking (MPPT) algorithm [24]-[26], the absorbed power by the generator can be maximized and optimized [27]. Section I introduces the linear generator and its mathematical modeling. In Section III, the MPPT algorithm, namely the complexconjugate control algorithm, is presented. In Section IV, the performances of wave power generation using this MPPT algorithm is verified and evaluated.

\section{LINEAR MAGNETIC-GEARED PERMANENT-MAGNET GENERATOR}

There are two different ways for integrating the linear magnetic gear with the linear PM machine. By sharing the same translator, the high-speed mover of the linear magnetic gear can be mechanical coupled with the translator of the linear PM machine in series or parallel style. For the series integration, the two moving parts are magnetically decoupled and can be designed individually. Therefore, this way is more flexible. For the parallel integration, the integrated gearedmachine is much more compact which may results in three airgaps and the two moving parts usually are magnetically coupled. In this paper, as shown in Fig. 1, the series integration of the magnetic-geared machine is chosen since the two machines are magnetically decoupled. The mathematical modeling for the magnetic-geared machine can be established independently.

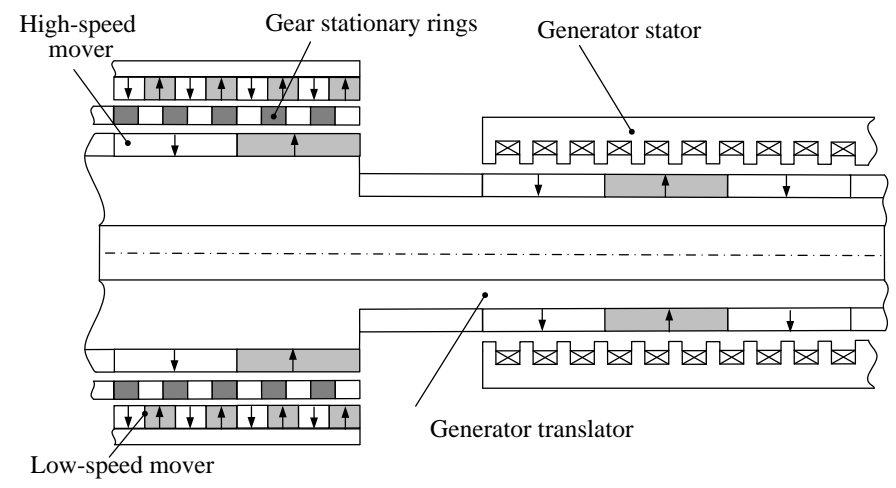

Fig. 1. Linear magnetic-geared permanent-magnet generator. 


\section{A. Linear Magnetic Gear}

Compared to the mechanical counterparts, the magnetic gear has the following advantages: high force density, high efficiency and high reliability, low acoustic noise, inherent overload protection, and free of maintenance. As shown in Fig. 1, the linear magnetic gear consists of two moving parts-the high-speed mover and the low-speed mover and one stationary part-the stationary rings for field modulation. PMs are surface-mounted on the high-speed mover and the lowspeed mover. The stationary rings consist of iron lamination only. In this design, the pole-pair number of PMs on the highspeed mover and low-speed mover are 4 and 23 . The number of field modulation segments is 27 . Thus, the magnetic gear ratio is 5.75 .

For each mover of the linear magnetic gear, the force exerted on the mover parallel to the motion direction consists of two components, namely the force developed by two magnetic fields interaction and the cogging force generated by the magnetic field and the stationary modulation rings. The thrust of the low-speed mover can be expressed as:

$$
F_{e m-L}(x)=F_{H-L}(x)+F_{\operatorname{Cog}_{-L}}(x)
$$

where the first item is due to the interaction between the modulated magnetic field of PMs on the high-speed mover and the fundamental magnetic field of PMs on the low-speed mover.

Similarly, the thrust of the high-speed mover can also be given by:

$$
F_{e m-H}(x)=F_{L-H}(x)+F_{C o g-H}(x)
$$

As shown in Fig. 2, the force characteristics of the linear magnetic gear are obtained using the finite element analysis (FEA) when the high-speed mover travels at $1 \mathrm{~m} / \mathrm{s}$ and the low-speed mover is kept stationary. From this information, the first item of (2) and (3) can be determined. Similarly, the cogging force components can also be calculated.

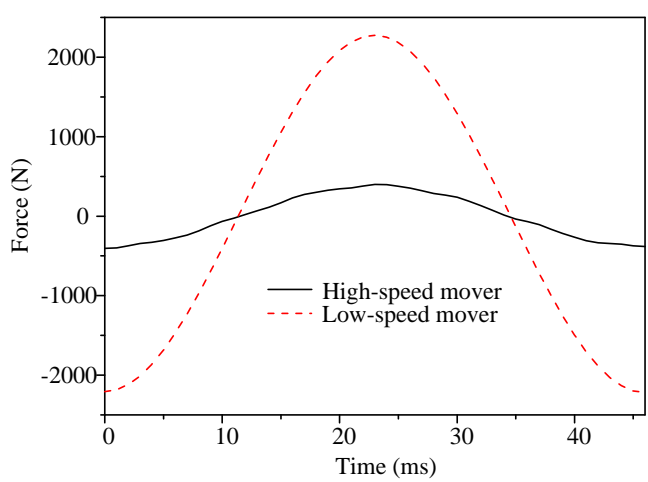

Fig. 2. Linear magnetic-gear force characteristics.

\section{B. Linear Permanent-Magnet Generator}

The linear PM machine adopts the conventional PM synchronous machine which has 10-pole and 12-slot configuration. The 5-pole-pair PMs are surface-mounted on the translator. For minimizing the cogging force, the stator adopts an ironless configuration. Six sets of the 3-phase winding are concentrated-wound in the stator.

Fig. 3 illustrates the no-load electromotive force (EMF) waveforms via FEA. The winding inductances are also computed based on FEA. The self-inductance is $3.7 \mathrm{mH}$ and the mutual-inductance is $0.37 \mathrm{mH}$. Therefore, the voltage equation is expressed as:

$$
V_{o}=\frac{d \psi_{s}}{d x} \frac{d x}{d t}-\frac{d L_{s}}{d x} \frac{d x}{d t} i_{s}-r_{s} i_{s}
$$

Similarly, the thrust of the linear PM machine can also be given by:

$$
\begin{aligned}
& F_{e m-G}=p\left(\frac{1}{2} i_{s}^{T} \frac{d L_{s}}{d x} i_{s}+i_{s}^{T} \frac{d \psi_{s}}{d x}\right) \\
& F_{e m-G}=-\frac{3 \pi}{2 \tau} \psi_{P M} i_{q}
\end{aligned}
$$

where $V_{o}$ is the terminal voltage, $\psi_{s}$ is the stator flux linkage matrix, $\psi_{P M}$ is the stator flux linkage due to PMs, $L_{s}$ is the stator inductance matrix, $i_{s}$ is the stator current vector, $x$ is the translator displacement, and $r_{s}$ is the stator winding resistance vector and $\tau$ is the PM pole-pitch. Eq. (5) is the thrust expression in $d q 0$-frame.

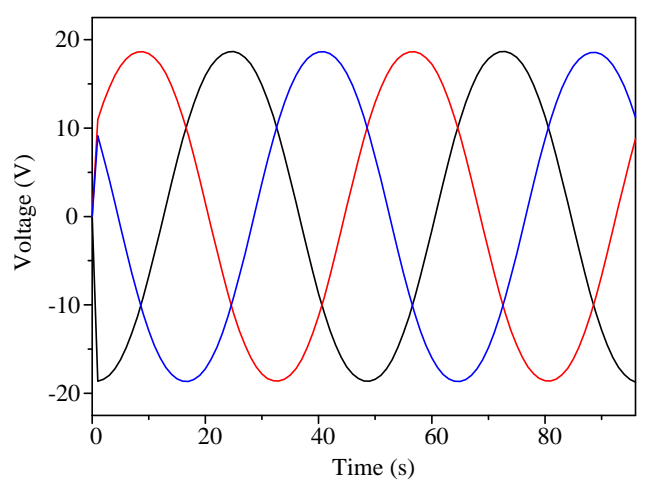

Fig. 3. No-load EMF waveforms of the linear generator.

The linear magnetic-geared permanent-magnet generator is designed based on Table I. Based on (1)-(5), the mathematical modeling of the integrated generator can be established [28].

\section{MPPT ALGORITHM}

Since wave power is a variable power source with oscillating nature, how to maximize the absorbed power becomes an important issue. As shown in Fig. 4(a) and (b), for the point absorber, it has the vertical and horizontal motion which can make symmetrical and asymmetrical waves. Theoretically, by combining these two motions, the wave energy from incident waves can be fully captured. As shown in Fig. 4(d), based on the amplitude control and the phase control, the wave energy converter should have the same amplitude as the incident wave and whereas the phase angle is 180 out of that of the incident wave. For the direct-drive wave energy converter, especially for those point-absorbers, since its movement only in the vertical direction is utilized, a half of the wave energy can be extracted for those monochromatic waves [29]. 
TABLE I. Design Data of Linear MagnetiC-GeARED Machine

\begin{tabular}{|l|l|}
\hline Gear outside diameter & $120 \mathrm{~mm}$ \\
\hline Gear inside diameter & $40 \mathrm{~mm}$ \\
\hline Gear active axial length & $184 \mathrm{~mm}$ \\
\hline Gear low-speed mover outside diameter & $120 \mathrm{~mm}$ \\
\hline Gear low-speed mover inside diameter & $94 \mathrm{~mm}$ \\
\hline Mass of gear low-speed mover & $8.76 \mathrm{~kg}$ \\
\hline Gear high-speed mover outside diameter & $78 \mathrm{~mm}$ \\
\hline Gear high-speed mover inside diameter & $40 \mathrm{~mm}$ \\
\hline Gear stationary ferromagnetic ring thickness & $6 \mathrm{~mm}$ \\
\hline Mass of gear high-speed mover & $4.9 \mathrm{~kg}$ \\
\hline Air-gap length & $1.0 \mathrm{~mm}$ \\
\hline No. of active pole-pairs in low-speed mover & 23 \\
\hline No. of active stationary ferromagnetic rings & 27 \\
\hline No. of active pole-pairs in high-speed mover & 4 \\
\hline PM remanence & $1.2 \mathrm{~T}$ \\
\hline No. of phases & 3 \\
\hline Rated voltage & $100 \mathrm{~V}$ \\
\hline Generator stator inside diameter & $60 \mathrm{~mm}$ \\
\hline Generator stator axial length & $248 \mathrm{~mm}$ \\
\hline Generator translator outside diameter & $58 \mathrm{~mm}$ \\
\hline Generator translator inside diameter & $30 \mathrm{~mm}$ \\
\hline Generator translator active axial length & $240 \mathrm{~mm}$ \\
\hline Mass of generator translator & $6.3 \mathrm{~kg}$ \\
\hline Overall active axial length & $368 \mathrm{~mm}$ \\
\hline
\end{tabular}

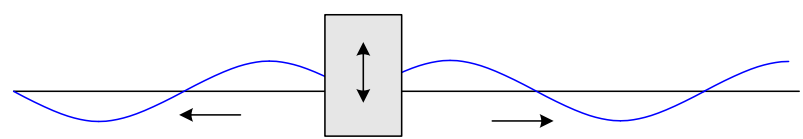

(a)

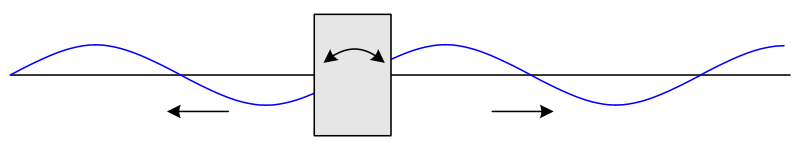

(b)

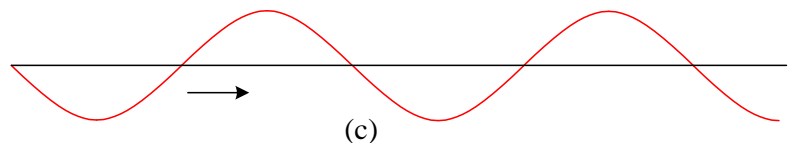

(c)

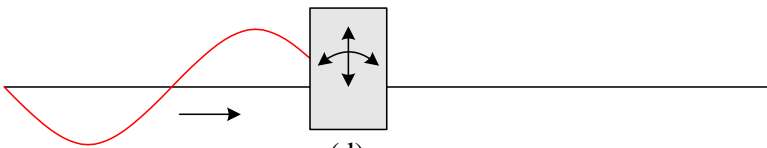

(d)

Fig. 4. Principle of wave energy extraction for a point-absorber. (a) Wave produced by a point-absorber in vertical motion. (b) Wave produced by a point-absorber in horizontal motion. (c) Incident wave. (d) Ideal case for wave energy extraction.

The hydrodynamic model of the point-absorber is expressed as [30]:

$$
F_{e}-F_{r}-F_{s}-F_{d}=m \frac{d^{2} x}{d t^{2}}
$$

where $F_{e}$ is the excitation force from the wave, $F_{r}$ is the radiation force of the point absorber, $F_{s}$ is the hydrostatic force, $F_{d}$ is the damping force of the point absorber, $m$ is the system mass and $x$ is the displacement of the moving part.

The radiation force is given by [30]:

$$
F_{r}=A(\omega) \frac{d^{2} x}{d t^{2}}+B(\omega) \frac{d x}{d t}
$$

where $A(\omega)$ is the added mass around the buoy and $B(\omega)$ is the energy loss due to the incident waves.

The hydrostatic force is given by [30]:

$$
F_{s}=\rho g S_{a} x
$$

where $\rho$ is the density of water and $S_{a}$ is the wetted area of the buoy.

The damping force of the linear generator is given by [30]:

$$
F_{d}=\gamma \frac{d x}{d t}+K x
$$

where $\gamma$ is the force coefficient related to the velocity and $K$ is the hydrodynamic stiffness.

Therefore, by combining (6)-(9), the excitation force of the coming waves can be expressed as:

$$
F_{e}=[m+A(\omega)] \frac{d^{2} x}{d t^{2}}+[\gamma+B(\omega)] \frac{d x}{d t}+\left(\rho g S_{a}+K\right) x
$$

The maximum power absorption is obtained when the natural frequency of the wave energy converter coincides with the wave frequency which means that the velocity of the point-absorber is in phase with the excitation force $F_{e}$. In the electrical analogue [31], the impedance of the linear generator should be the complex conjugate of the wave energy converter:

$$
Z_{L G}=Z_{W E C}^{*}
$$

Therefore, by forcing the wave energy converter in resonance with the waves, the absorbed power can be maximized. This algorithm is called "complex-conjugate control" which is also known as "reactive control".

\section{PERFormance VERIFICATION}

For verifying performances of MPPT algorithm for proposed linear magnetic-geared generator, the linear magnetic-geared is connected to a dc source via a voltage source converter (VSC) which enables the bi-directional power flow between the generator and the dc source [32].

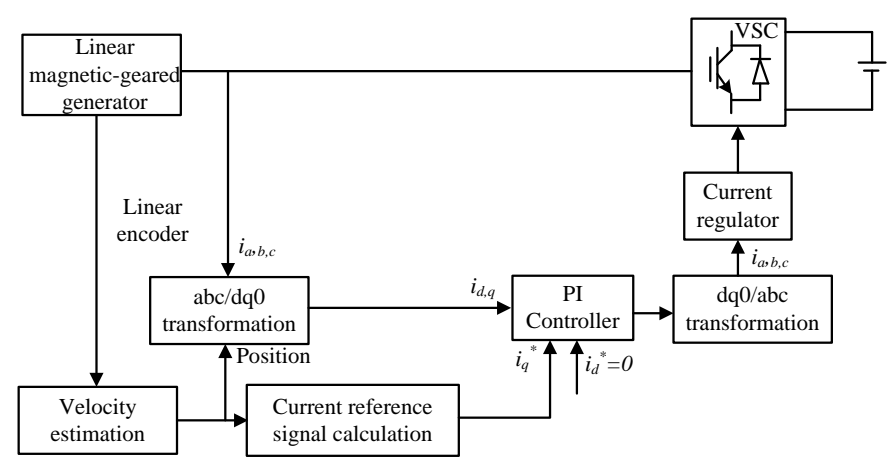

Fig. 5. Control block diagram for the wave power generation system 
Fig. 5 shows the corresponding control block diagram of the proposed wave power generation system for verifying the MPPT algorithm. The control system aims to regulate the linear generator thrust force via the linear generator current control to achieve the complex-conjugate control. By controlling the generator thrust, the impedance of the generator should be similar as the complex conjugate of the wave energy converter. Therefore, the wave energy converter can resonantly operate with the incident waves and the absorbed power can be maximized. The translator velocity of the linear generator and its position are estimated via the linear encoder. Then, using the field-oriented control, the reference signal of quadrature-axis current can be calculated based on the translator velocity information. In addition, an abc/dq0 transformation for the direct-axis and quadrature-axis current reference signals are obtained based on the translator position information. By comparing the actual current signal with the current reference signal, the error signals are feed into a PI controller for generating a set of control pulse signal. With these firing signals, power switches of VSC are turned on or off for tracing the reference signal.

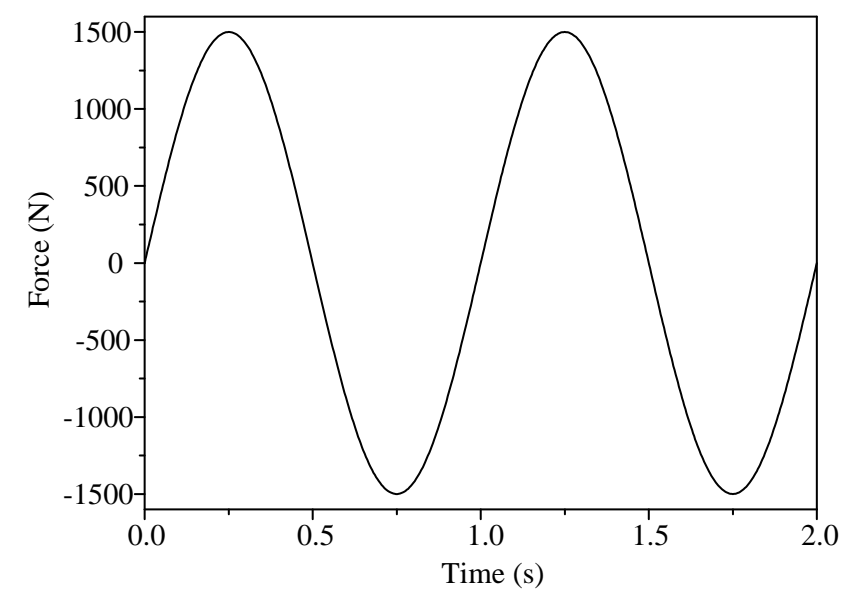

Fig. 6. Force exerted on the buoy by incident waves.

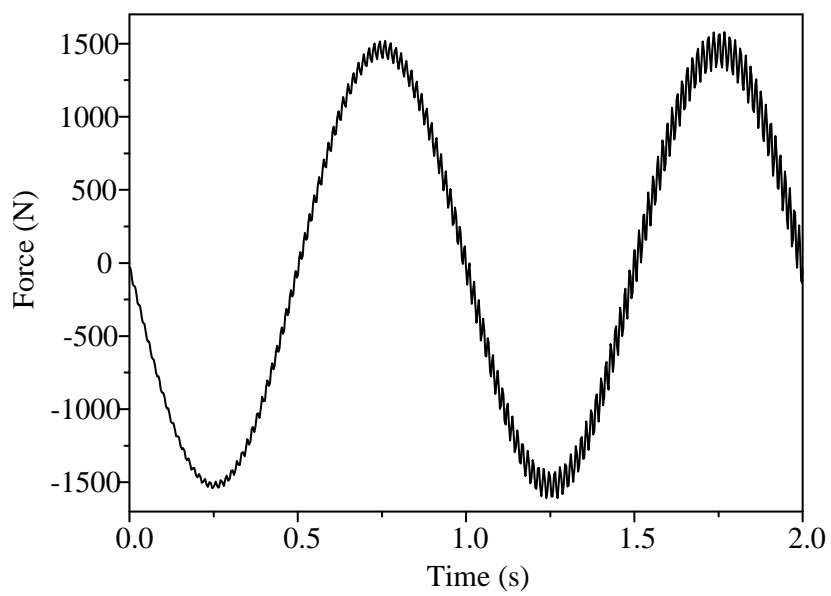

Fig. 7. Low-speed mover force waveform.

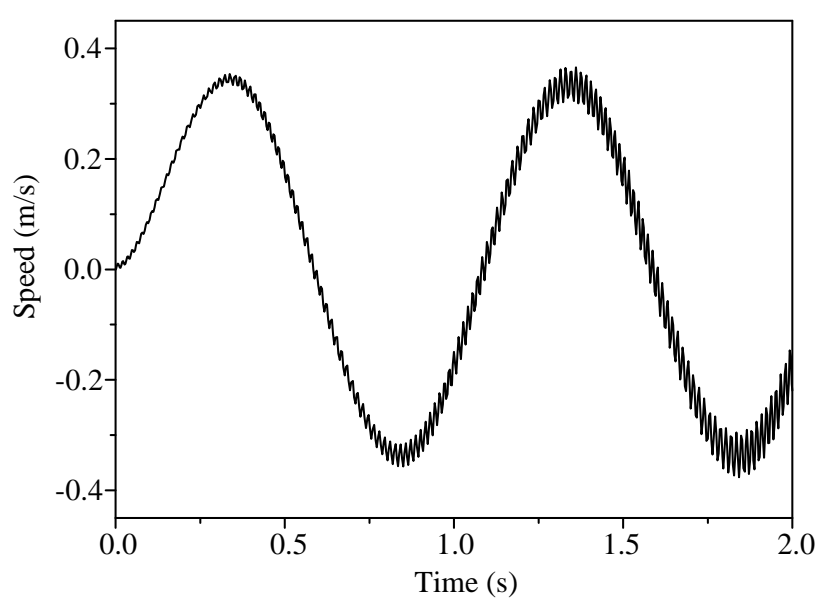

Fig. 8. Low-speed mover speed waveform.

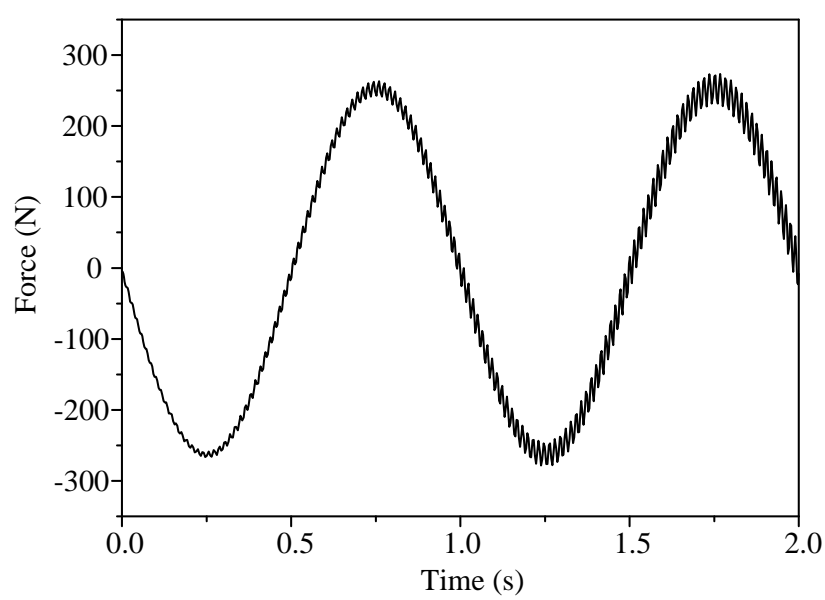

Fig. 9. High-speed mover force waveform.

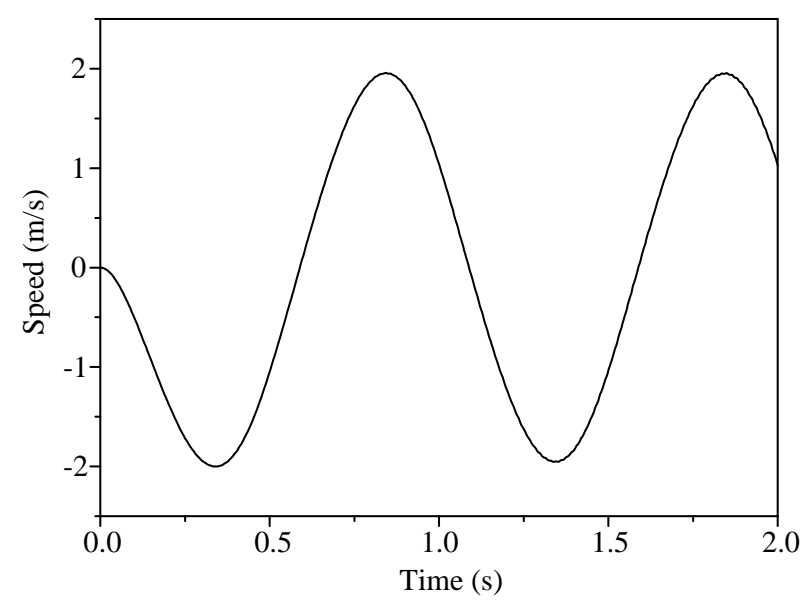

Fig. 10. High-speed mover speed waveform. 


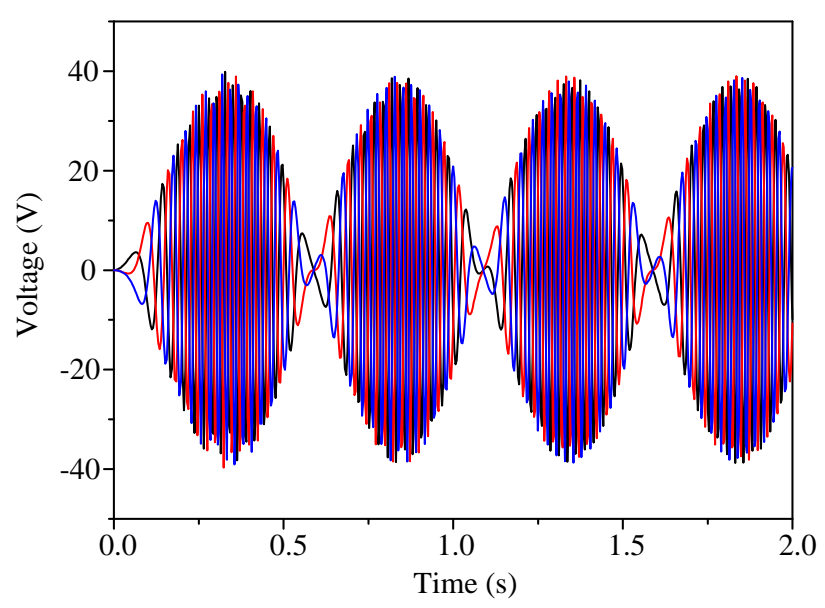

Fig. 11. Voltage waveforms of linear generator

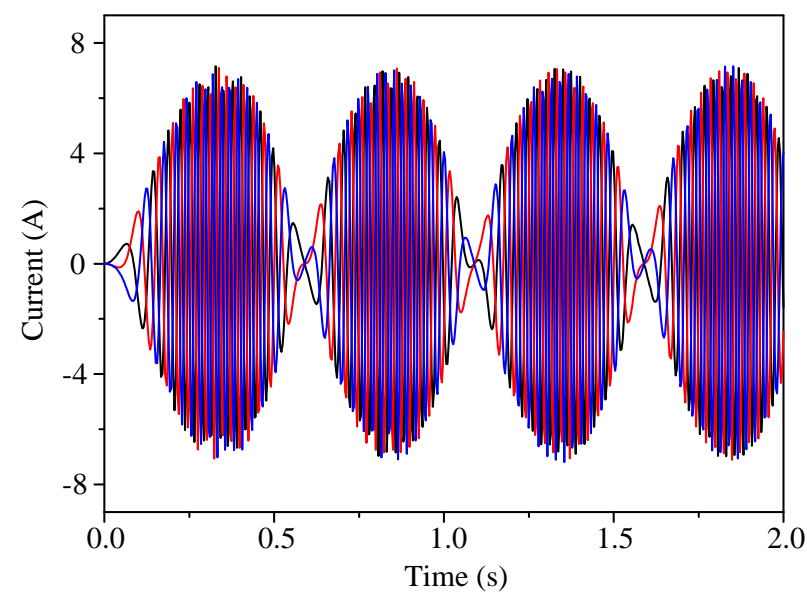

Fig. 12. Current waveforms of linear generator

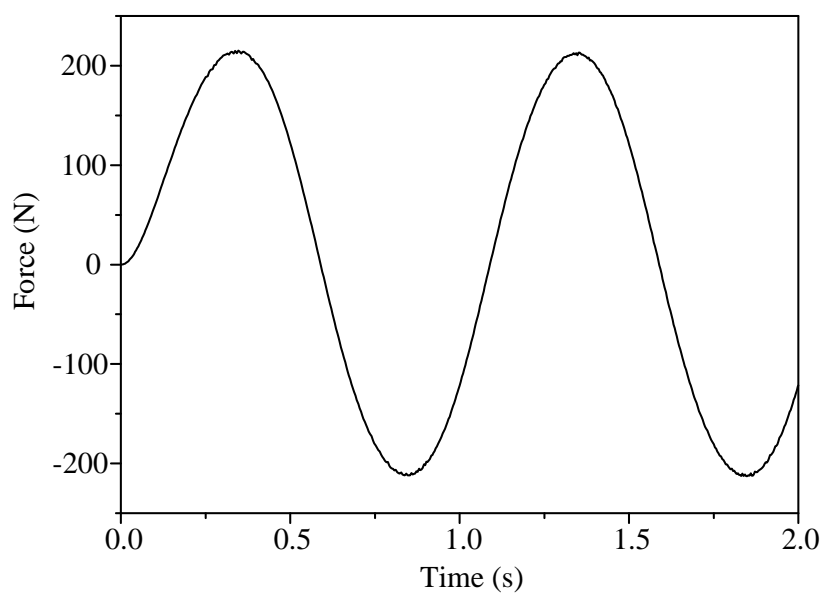

Fig. 13. Thrust force waveform of linear generator

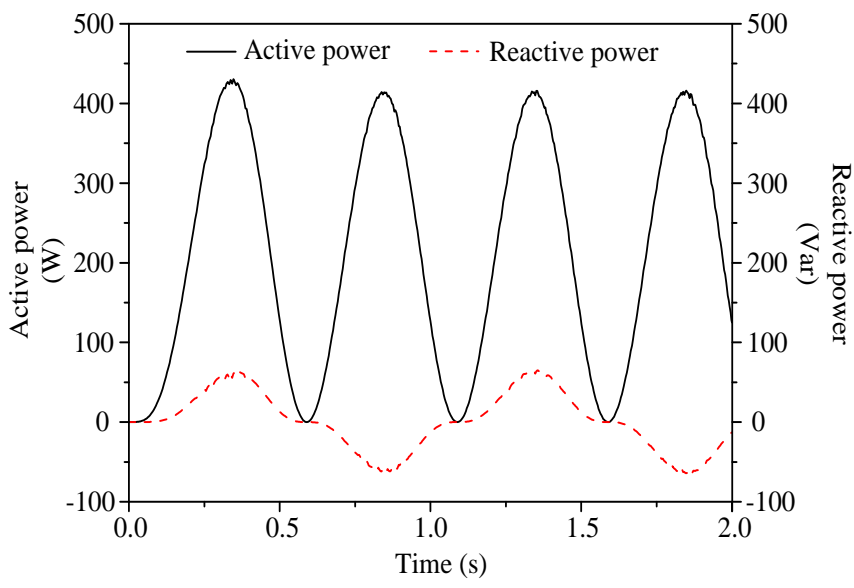

Fig. 14. Active power and reactive power of linear generator.

In this paper, only monochromatic waves which exert on the buoy of the point absorber are considered and the incident waves in the simulation are considered as pure sinusoidal. Fig. 6 shows the force exerted on the buoy which is sinusoidal with amplitude of $1500 \mathrm{~N}$ and a frequency of $1 \mathrm{~Hz}$. Since the buoy is connected to the low-speed mover of the linear magneticgeared generator, the low-speed mover is driven by the buoy and the high-speed mover and the linear generator translator moves with an amplified speed caused by the magnetic gear effect. Fig. 7 and Fig. 8 show the thrust force and speed waveforms of the low-speed mover respectively. The speed of the low-speed mover is sinusoidal with amplitude of $0.34 \mathrm{~m} / \mathrm{s}$. Fig. 9 and Fig. 10 illustrate the thrust force and speed waveforms of the high-speed mover respectively. The force of the high-speed mover is also sinusoidal with amplitude of 260 $\mathrm{N}$. The speed of the high-speed mover is sinusoidal with amplitude of 1.96. Thus, the force of the wave is scaled down by a ratio of 5.75 by the linear magnetic gear and the speed of the buoy is scaled up by a ratio of 5.75. The low-speed and high-force-density of wave energy is converted into an energy source in form of high-speed and low-force density feature.

Fig. 11 and Fig. 12 show the voltage and current waveforms of the linear generator. Due to the speed amplification of the linear magnetic gear, the voltage amplitude of the linear generator is improved. By using the MPPT algorithm and field-oriented control, the current is nearly in phase with the voltage waveform. Fig. 13 shows the translator force waveform of the linear generator. It can be found that the linear generator force has a correct phase relationship with the buoy force waveform. Because of control of the linear generator force, the wave energy converter is in resonance with the incident waves. Therefore, the absorbed power from waves can be maximized. Fig. 14 shows the power waveforms of the linear generator. It can be observed that the active power has amplitude of $440 \mathrm{~W}$ and the reactive power has amplitude of 58 var and the negative reactive power indicates that the power flows back into the linear generator for ensuring the wave energy converter operating resonantly with the waves. 


\section{CONCLUSION}

In this paper, a linear magnetic-geared permanent-magnet generator is adopted for the direct-drive wave power generation. In order to maximize the absorbed power, the MPPT algorithm, namely the complex-conjugate control, is applied which forces the wave energy converter operating resonantly with the incident waves. By using the FEM, the linear magnetic gear and the linear generator parameters are calculated. With these parameters, the mathematical modeling of the linear magnetic-geared generator is established. Then, the maximum power absorption condition is discussed and the MPPT algorithm is developed. For assessing the MPPT algorithm, the linear magnetic-geared generator is connected to a dc source via a voltage source converter, due to the bidirectional power flow, the wave energy converter operates resonantly with the incident waves. The results show that the absorbed power can be maximized by using the MPPT algorithm.

\section{REFERENCES}

[1] H. Polinder, B.C. Mecrow, A.G. Jack, P.G. Dickinson, and M.A. Mueller, "Conventional and TFPM linear generators for direct-drive wave energy conversion," IEEE Transactions on Energy Conversion, vol. 20, no. 2, June 2005, pp. 260- 267.

[2] F.O. Antonio, "Wave energy utilization: A review of the technologies," Renewable and sustainable energy reviews, vol.14, no.3, 2010, pp. 899918.

[3] L. Ran, M.A. Mueller, C. Ng, P.J. Tavner, H. Zhao, N.J. Baker, S. McDonald, P. McKeever, "Power conversion and control for a linear direct drive permanent magnet generator for wave energy," IET renewable power generation, vol. 5, no.1, 2011, pp.1-9.

[4] R. Vermaak and M.J. Maarten, "Design aspects of a novel topology aircored permanent magnet linear generator for direct drive wave energy converters," IEEE Transactions on Industrial Electronics, vol.59, no.5, 2012, pp.2104-2115.

[5] Y. Fan, K.T. Chau and M. Cheng, "A new three-phase doubly salient permanent magnet machine for wind power generation," IEEE Transactions on Industry Applications, vol. 42, no. 1, January/February 2006, pp. 53-60.

[6] K.T. Chau and C.C. Chan, "Emerging energy-efficient technologies for hybrid electric vehicles," Proceedings of IEEE, vol. 95, no. 4, April 2007, pp. 821-835.

[7] S. Niu, K.T. Chau, J.Z. Jiang and C. Liu, "Design and control of a new double-stator cup-rotor permanent-magnet machine for wind power generation," IEEE Transactions on Magnetics, vol. 43, no. 6, June 2007, pp. 2501-2503.

[8] K.T. Chau, C.C. Chan and C. Liu, "Overview of permanent-magnet brushless drives for electric and hybrid electric vehicles," IEEE Transactions on Industrial Electronics, vol. 55, no. 6, June 2008, pp. 2246-2257.

[9] C. Liu, K.T. Chau, J.Z. Jiang and L. Jian, "Design of a new outer-rotor permanent magnet hybrid machine for wind power generation," IEEE Transactions on Magnetics, vol. 44, no. 6, June 2008, pp. 1494-1497.

[10] W. Li, K.T. Chau, C. Liu, S. Gao, and D. Wu, "Analysis of tooth-tip flux leakage in surface-mounted permanent magnet linear vernier machines," IEEE Transactions on Magnetics, vol. 49, no. 7, July 2013, pp.39493952.

[11] K. Atallah and D. Howe, "A novel high-performance magnetic gear," IEEE Transactions on Magnetics, vol. 37, no. 4, 2001, pp. 2844-2846.

[12] K. Atallah, S.D. Calverley, and D. Howe, "Design, analysis and realization of a high-performance magnetic gear", IEE Proceedings of Electric Power Applications, vol. 151, no. 2, March 2004, pp. 135-143.
[13] K.T. Chau, D. Zhang, J.Z. Jiang and L. Jian, "Transient analysis of coaxial magnetic gears using finite element comodeling," Journal of Applied Physics, vol. 103, no. 7, April 2008, paper no. 07F101, pp. 1-3.

[14] X. Liu, K.T. Chau, J.Z. Jiang and C. Yu, "Design and analysis of interior-magnet outer-rotor concentric magnetic gears," Journal of Applied Physics, vol. 105, no. 7, April 2009, paper no. 07F101, pp. 1-3.

[15] L. Jian, K.T. Chau, W. Li and J. Li, "A novel coaxial magnetic gear using bulk HTS for industrial applications," IEEE Transactions on Applied Superconductivity, vol. 20, no. 3, June 2010, pp. 981-984.

[16] W. Li, K.T. Chau and J. Li, "Simulation of a tubular linear magnetic gear using HTS bulks for field modulation," IEEE Transactions on Applied Superconductivity, vol. 21, no. 3, June 2011, pp. 1167-1170.

[17] M. Chen, K.T. Chau, W. Li, and C. Liu, "Quantitative comparison of linear magnetic gear with different types of PMs," Applied Mechanics and Materials, vol. 416-417, 2013, pp. 385-389.

[18] M. Chen, K.T. Chau, W. Li, and C. Liu, "Cost-effectiveness comparison of coaxial magnetic gears with different magnet materials," IEEE Transactions on Magnetics, vol. 50, no. 2, paper no. 7020304, February 2014, pp. 1-4.

[19] K.T. Chau, D. Zhang, J.Z. Jiang, C. Liu and Y.J. Zhang, "Design of a magnetic-geared outer-rotor permanent-magnet brushless motor for electric vehicles," IEEE Transactions on Magnetics, vol. 43, no. 6, June 2007, pp. 2504-2506.

[20] L. Jian, K.T. Chau and J.Z. Jiang, "A magnetic-geared outer-rotor permanent-magnet brushless machine for wind power generation," IEEE Transactions on Industry Applications, vol. 45, no. 3, 2009, pp.954-962.

[21] W. Li and K.T. Chau, "A linear magnetic-geared free-piston generator for range-extended electric vehicles," Journal of Asian Electric Vehicles, vol. 8, no. 1, June 2010, pp. 1345-1350.

[22] X. Li, K.T. Chau, M. Cheng and W. Hua, "Comparison of magneticgeared permanent-magnet machines," Progress In Electromagnetics Research, vol. 133, 2013, pp. 177-198.

[23] W. Li, K. T. Chau, and J. Z. Jiang, "Application of linear magnetic gears for pseudo-direct-drive oceanic wave energy harvesting," IEEE Transactions on Magnetics, vol. 47, no. 10, October 2011, pp. 26242627.

[24] C. Yu and K.T. Chau, "Thermoelectric automotive waste heat energy recovery using maximum power point tracking," Energy Conversion and Management, Vol. 50, No. 6, June 2009, pp. 1506-1512.

[25] X. Zhang and K.T. Chau, "An automotive thermoelectric-photovoltaic hybrid energy system using maximum power point tracking," Energy Conversion and Management, vol. 52, no. 1, January 2011, pp. 641-647.

[26] X. Zhang and K.T. Chau, "Design and implementation of a new thermoelectric-photovoltaic hybrid energy system for hybrid electric vehicles," Electric Power Components and Systems, vol. 39, no. 6, April 2011, pp. 511-525.

[27] E.A. Amon, T.K.A. Brekken, and A.A. Schacher, "Maximum power point tracking for ocean wave energy conversion," IEEE Transactions on Industry Applications, vol. 48, no. 3, 2012, pp.1079-1086.

[28] O.A. Mohammed, S. Liu, and Z. Liu, "Physical modeling of PM synchronous motors for integrated coupling with machine drives," IEEE Transactions on Magnetics, vol. 41, no. 5, 2005, pp.1628-1631.

[29] J. Falnes. Ocean waves and oscillating systems: linear interactions including wave-enenrgy extraction. Cambridge University Press, 2002.

[30] R. Ekstrom, B. Ekergard, and M. Leijon, "Electrical damping of linear generators for wave enerngy converters-A review," Renewable and Sustainable Energy Reviews, vol. 42, 2015, pp.116-128.

[31] E. Tedeschi and M. Molinas, "Control strategy of wave energy converters optimized under power electronics rating constraints," Proceeding of 3rd International Conference on Ocean Energy, October 6-8, 2010, Bilbao, Spain.

[32] V. DelliColli, P. Cancelliere, F. Marignetti, R. DiStefano, and M. Scarano,"A Tubular-Generator Drive For Wave Energy Conversion," IEEE Transactions on Industrial Electronics., vol. 53, no. 4, 2006, pp.1152-1159. 